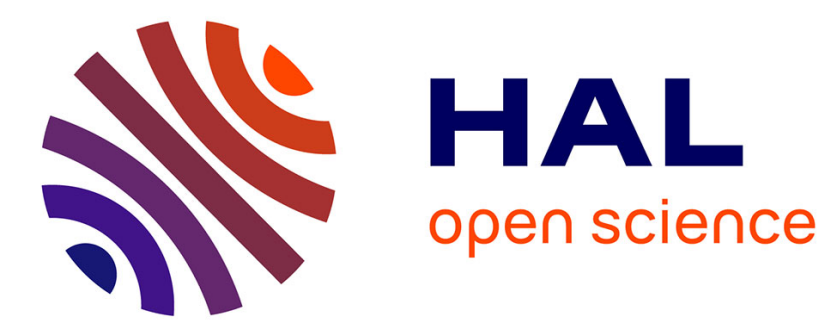

\title{
Fundamental Input of Analytical Electrochemistry in the Determination of Intermediates and Reaction Mechanisms in Electrosynthetic Processes
}

Eric Labbé, Olivier Buriez

\section{- To cite this version:}

Eric Labbé, Olivier Buriez. Fundamental Input of Analytical Electrochemistry in the Determination of Intermediates and Reaction Mechanisms in Electrosynthetic Processes. ChemElectroChem, 2019, 6 (16), pp.4118-4125. 10.1002/celc.201900045 . hal-02303634

\section{HAL Id: hal-02303634 \\ https://hal-ens.archives-ouvertes.fr/hal-02303634}

Submitted on 2 Oct 2019

HAL is a multi-disciplinary open access archive for the deposit and dissemination of scientific research documents, whether they are published or not. The documents may come from teaching and research institutions in France or abroad, or from public or private research centers.
L'archive ouverte pluridisciplinaire HAL, est destinée au dépôt et à la diffusion de documents scientifiques de niveau recherche, publiés ou non, émanant des établissements d'enseignement et de recherche français ou étrangers, des laboratoires publics ou privés. 


\title{
The fundamental input of analytical electrochemistry in the determination of intermediates and reaction mechanisms in electrosynthetic processes.
}

\author{
Eric Labbé * and Olivier Buriez * \\ This review is dedicated to Professor Jacques Périchon, who implemented and generalized the sacrificial anode in electrosynthetic \\ chemistry, on the occasion of his $80^{\text {th }}$ anniversary
}

\begin{abstract}
Electroanalytical techniques like cyclic voltammetry allow convenient and fast identification of the redox status and stability of the intermediates generated at electrodes in electrosynthetic processes. Accordingly, reliable mechanistic features can also be derived from the electrochemical characterization of the reactive species, and in some cases complete and complex mechanisms can be disclosed. This minireview highlights some representative examples taken from metal-catalyzed electroreductive processes where simple electrochemical approaches provide essential information on the nature and the fate of the species formed. A special focus is made on cobalt-promoted electrosynthetic processes owing to the broad range of situations they display towards the stability of electrogenerated species, their reactivity and the possible follow-up reactions.
\end{abstract}

\section{Introduction}

Electrosynthetic methods have regained considerable attention in the last 15 years, as assessed by the number of recent reviews dealing with the general ${ }^{[1]}$, preparative ${ }^{[2]}$, and technological ${ }^{[3]}$ aspects of organic electrosynthesis. Moreover, the commercial availability of "all-in-one" electrosynthesis setups (viz. featuring the electrochemical cells, electrodes and power supply) contributes to the fast dissemination of electrochemical methods among synthetic chemists. However, if presented as sustainable and now accessible, electrosynthetic processes generate species at electrodes which are unstable by nature (in other words highly reactive) and the exact sequence of reactions triggered once the power supply is switched "ON" often remains unknown to the operator. In that context, the lack of control of the thermodynamics (tunable from the electrode potential) and kinetics (related to the current intensity) may affect the selectivity of electrosynthetic processes, mostly through the broadening of product distribution, favoring the occurrence of side reactions. Although this aspect remains poorly discussed, electrosynthesis in static (non-flow) cells is a process where the composition of the reaction medium dramatically changes with the coulometric charge passed, potentially modifying the nature of electrode reactions and consecutive steps. Considering that the selectivity in a synthetic procedure is strongly related to the capacity to favor a specific reaction sequence, the knowledge of at least the

Eric Labbé and Olivier Buriez

PASTEUR, Département de chimie, École normale supérieure, PSL

University, Sorbonne Université, CNRS, 75005 Paris, France

E-mail: eric.labbe@ens.fr; olivier.buriez@ens.fr initial steps of an electrolytic process is of crucial importance if one intends to implement, explain or improve an electrosynthetic route. With this respect, the question of the actual nature of the species generated upon electrochemical reduction or oxidation must be addressed first. In this review, we propose a general survey showing how an electroanalytical knowledge-based approach mostly involving cyclic voltammetry, strengthens the determination of the nature of the reactive intermediates formed, their lifetimes and their reactions. The examples will be essentially taken from electrosynthetic processes featuring transition metal catalysts, owing to the large range of reaction types they provide (electron transfer, complexation, oxidative addition, reductive elimination,...). The first section is devoted to the electrochemical characterization of the "active" species generated electrochemically, with respect to the electrosynthetic process of interest whereas the second one deals with the determination of reaction sequences posterior to this initial electrochemical step.

Prof. Eric Labbé received his $\mathrm{PhD}$ in Analytical Chemistry in 1992 from Université Pierre et Marie Curie. He started studying electrosynthetic mechanisms in the group of Jacques Périchon between 1993 and 2005. Since 2006, he is Professor at Sorbonne Université and his research topics concern the electroanalytical determination of reaction mechanisms, drug metabolism and drug vectorization across membranes.

Dr. Olivier Buriez received his PhD in 1996, in Molecular Electrochemistry, under the supervision of $\mathrm{Dr}$ C. Amatore and J.N. Verpeaux (ENS-Paris). After a postdoctoral research at the Berkeley Lab. (LBNL, Univ. of California, USA; with J.B. Kerr and R.H. Fish), he obtained a CNRS permanent position in 1999 where he's now Research Director. Since 2015, he's Officer of the Molecular Electrochemistry Division of the International Society of Electrochemistry G (ISE).

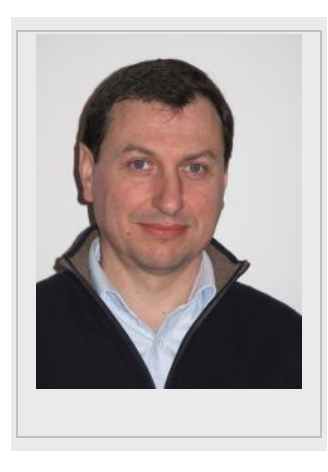




\section{Electrochemical determination of the redox state, stability and reactivity of electrogenerated species.}

The very first issue which arises upon discussing the reactivity and fate of electrogenerated species is their redox state and stability, i.e. the starting point of any ascertainable reaction sequence ${ }^{[4]}$. Electrosynthetic processes featuring transition metal catalysts provide examples where the initial electrochemical step locally generates unstable/reactive reduced metal complexes from stable precursors. In this paragraph we specifically focus on the key issue of determining i) the redox state and stability and ii) the reactivity of electrogenerated catalysts from selected examples taken from transition metal catalyzed reductive processes.

\subsection{Exploring the redox properties and stability of electrogenerated products by linear and cyclic voltammetry: the example of cobalt complexes.}

In this paragraph, we present examples featuring cobalt as the metal since its electrochemistry encompasses a comprehensive range of ligand- and solvent- directed effects on the stability and hence on the reactivity of the resulting cobalt complexes.

\subsubsection{Stabilization of cobalt(I) by various ligands.}

Within the cobalt family, macrocyclic cobalt(II) complexes such as vitamin $B_{12}$ derivatives, cobalt porphyrins and cobalt-salen analogs received much attention thanks to the high nucleophilicity of the reduced cobalt(I) compounds towards $\mathrm{C}\left(\mathrm{sp}^{3}\right)$-halogen bonds. Mechanistic investigations of these reactions were facilitated by its high stability which leads to "quasi perfect" well-defined reversible waves, giving rise to numerous electroanalytical studies ${ }^{[5]}$ that we will develop in the next paragraph.

Conversely, low-coordinated / less stable cobalt(I) complexes give less reversible cyclic voltammograms, a fact that frequently turns down their exploration as possible electrogenerated catalysts. Actually, it is in these "uncomfortable" electroanalytical situations that most of the interesting reactivities (and synthetic potentialities) have been discovered. In the following, are given a series of typical examples in which cyclic voltammetry was "smartly" used to rationalize the stability/reactivity duality of low-valent and weakly coordinated cobalt species as a function of crucial parameters such as the nature of the solvent, co-solvent, ligands, electrode material, etc...

The most reactive cobalt(I) species described are obtained from more weakly coordinated complexes, i.e. those generated by reduction of simple cobalt(II) salts of the type $\mathrm{CoX}_{2}(\mathrm{X}=\mathrm{Br}, \mathrm{Cl}$, $\left.\mathrm{BF}_{4}\right)$. In classical organic solvents (MeCN, DMF), electrogenerated cobalt $(I)$ species undergo very fast disproportionation reactions leading to inactive cobalt deposits $\left(\mathrm{Co}_{(\mathrm{s})}\right)$ on electrode surfaces (see Scheme 1). Under these conditions, the cyclic voltammogram showed an irreversible 2electrons reduction wave followed, on the backward scan, by an oxidation process corresponding to the anodic stripping of the solid cobalt deposited on the electrode surface (a typical cyclic voltammogram is shown at the top of Figure 1). Importantly, the use of pyridine as co-solvent (10\% in volume) allowed stabilization of the electrogenerated cobalt(I) species at short time scales as observed in cyclic voltammetry, displaying a fully reversible monoelectronic wave at $20 \mathrm{~V} / \mathrm{s}$. Under these conditions, the reduction of $\mathrm{Co}(\mathrm{I})$ to coordinated $\mathrm{Co}(0)$ could be even evidenced for the first time. Accordingly, a study of the reversibility of the reduction wave of the cobalt(II) species versus the scan rate allowed determination of the rate constant $k_{\text {disp. }}$ for the disproportionation reaction of $\mathrm{Co}(\mathrm{I})$. The latter was found to be twice as stable as in a MeCN/pyridine than in a DMF/pyridine (9:1) mixture $\left(k_{\text {disp. }}=(1 \pm 0.25) \times 10^{3}\right.$ in $\mathrm{MeCN} /$ pyridine and $(2 \pm$ $0.50) \times 10^{3} \quad \mathrm{M}^{-1} \mathrm{~s}^{-1}$ in DMF/pyridine $)^{[6]}$.

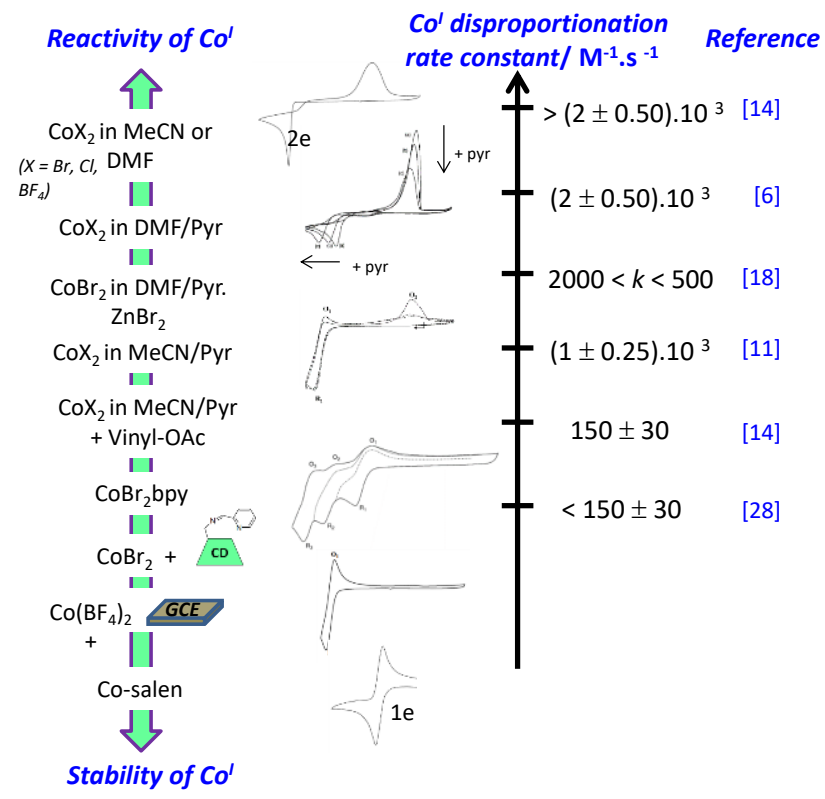

Figure 1. Stability of electrogenerated $\mathrm{Co}(\mathrm{I})$ towards disproportionation in various media, as assessed from the determination of its disproportionation rate constants by cyclic voltammetry.

Combination of pyridine used as a co-solvent and vinylic or allylic derivatives proved to be an interesting approach to further increase the stability of $\mathrm{Co}(\mathrm{I})$ via the formation of $\pi$-complexes. For instance, in MeCN/pyridine, the use of vinyl acetate (vinyl$\mathrm{OAc}$ ) as additive increased the stability of $\mathrm{Co}(\mathrm{I})$ (the disproportionation rate constant was seven times lower $k_{\text {disp. }}=$ $\left.150 \mathrm{M}^{-1} \mathrm{~s}^{-1}\right)^{[7]}$. Similarly, the use of allyl acetate is also efficient to stabilize the $\mathrm{Co}(\mathrm{I})$ species through the formation of a $\left(\eta^{2}\right.$-allylOAc)cobalt(I) complex ${ }^{[8]}$. In this case, a study of the potential shift obtained for the reduction wave of $\mathrm{CoBr}_{2}$ as a function of both the scan rate and the allyl acetate concentration allowed an estimation of the rate constant for the complexation reaction as being $\mathrm{k}_{0}=(15 \pm 3) \times 10^{3} \mathrm{M}^{-1} \cdot \mathrm{s}^{-1}$ that is 15 times higher than the disproportionation rate constant determined under the same solvent conditions (MeCN/pyridine ( $\mathrm{v} / \mathrm{v}=9: 1)$ mixture). The latter reaction can be therefore disregarded in the presence of allylOAc. In addition, a study of the shift of the half wave reduction 


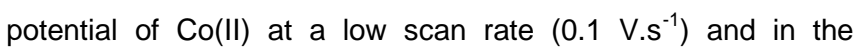
presence of increasing amounts of allyl acetate (from 25 to 100 $\mathrm{mM}$ ) allowed the determination of the thermodynamic constant $\mathrm{K}_{\mathrm{d}}$ for the complexation as being in the range $3.2 \leq \mathrm{pK}_{\mathrm{d}} \leq 3.3$ and showed that the allyl acetate:cobalt(I) complex had a $1: 1$ stoichiometry. Moreover, a fine investigation of the $\mathrm{Co}$ (II) peak current as function of the scan rate (and in the presence of allyl acetate) evidenced that the $\left(\eta^{2}\right.$-allyl-OAc)cobalt $(I)$ complex intermediate underwent a slow self-oxidative addition affording a $\left(\eta^{3}\right.$-allyl)cobalt(III) with a rate constant of $0.11 \pm 0.04 \mathrm{~s}^{-1}$. This sequence is summarized in Scheme 1. Interestingly, this value was in the same order found by $\mathrm{C}$. Amatore for the oxidative addition of allyl acetate to palladium $(0)$ complexes ligated by diphosphanes $^{[9]}$. The slow oxidative addition of ( $\eta 2$-allyl$\mathrm{OAc})$ cobalt $(\mathrm{I})$ allowed to observe its electrochemical reduction into the corresponding ( $\eta 2$-allyl-OAc)cobalt(0) by cyclic voltammetry.

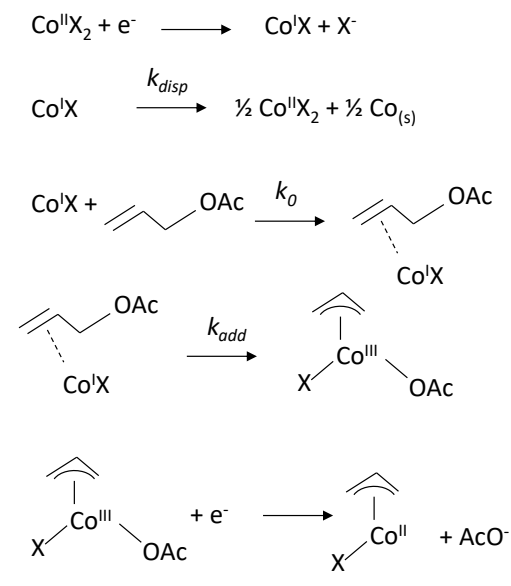

Scheme 1. Complexation of unstable Co' by allylic acetates and subsequent reduction sequence.

Preparative-scale electrolyses of cinnamyl acetate (used instead of allyl acetate in order to detect products more easily by gas chromatography) in the presence of $\mathrm{CoBr}_{2}$, and in a divided cell, demonstrated the formation of the dimer 1,6-diphenyl-1,5hexadiene from either $\left(\eta^{3}\right.$-allyl)cobalt(II) or $\left(\eta^{2}\right.$-allylOAc)cobalt $(0) .{ }^{[8]}$ However, the electroreductive process was not strictly catalytic since $\mathrm{CoBr}_{2}$ was progressively poisoned by acetate anions (coming from the allyl derivative) leading thus to cobalt(II) acetate species which were very stable and reduced at much more negative potential values. However, it was demonstrated that running electrolyses of cinnamyl acetate in an undivided cell, in the presence of iron(II) ions (generated by a sacrificial iron rod anode), could restore the cobalt to its initial form. Indeed, iron(II) ions generated at the sacrificial anode were more strongly complexed by acetate anions than cobalt(II). Thus, an acetate-free cobalt catalyst was regenerated.

In this quest for agents able to stabilize cobalt(I) species without poisoning it or reacting with it (non-innocent ligand), the electrochemical behavior of $\mathrm{CoBr}_{2}$ was investigated in the presence of allyl-ethers. It was shown that, in acetonitrile, allylic ethers stabilize the electrogenerated $\mathrm{Co}^{\prime}$ species, on the time scale of cyclic voltammetry, provided pyridine was used as cosolvent. This stabilization, which likely occurs via the formation of a $\pi$-complex of the type $\left(\eta^{2}\right.$-allyl-OR)Co'Br, has been proved to only involve one molecule of allylether per cobalt. The thermodynamic complexation constant has been determined and found lower than that obtained in the presence of allylic acetates ( $\mathrm{p} K_{\mathrm{d}}=1.90$ vs. 3.20-3.30) indicating a less stable, and consequently an expected more reactive cobalt(I) species. In agreement with this, no intramolecular oxidative addition of cobalt $(\mathrm{I})$ on the allylether has been evidenced during preparative electrolyse ${ }^{[10]}$. At this stage it is important to note that electrochemical techniques cannot give structural information (except the oxidation state of the metal) unless by comparison to authentic samples. When the latter are not available, the association of electrochemistry with namely spectroscopic techniques is necessary for the investigation of mechanisms.

Interestingly, the cobalt(I) species was also found to be stabilized by more classical ligands such as bipyridine, but through an unusual $1 / 1$ metal/ligand stoichiometry. The electrochemical behavior of $\mathrm{CoBr}_{2}$ bpy revealed the possibility to generate both $\mathrm{Co}^{\prime}$ and $\mathrm{Co}^{0}$ redox states in acetonitrile, the latter being stable only over few seconds ${ }^{[11]}$. Note that such $\mathrm{Co}^{0}-$ bipyridine complexes cannot be obtained from the stable $\mathrm{Co}(\mathrm{bpy})_{3}{ }^{2+}$ precursor which is generally preferred to carry out academic electroanalytical studies.

Interestingly, the cyclic voltammogram of $\mathrm{CoBr}_{2} \mathrm{bpy}$ exhibited three successive monoelectronic reduction waves. The absolute number of electrons was determined through the combination of stationary and transient electrochemical techniques, according to a method developed by C. Amatore ${ }^{[12]}$. In order to further characterize the nature of the complexes of $\mathrm{Co}^{\prime \prime}, \mathrm{Co}^{\prime}$ and $\mathrm{Co}^{\circ}$, the effect of bromide concentration on the cyclic voltammogram obtained for $\mathrm{CoBr}_{2}$ bpy was investigated. Indeed, $\mathrm{CoBr}_{2}$ bpy could either exist as a molecular (neutral) complex, or dissociate into a cationic moiety and bromide anions. Cyclic voltammetry and rotating disk voltammetry were used and showed that the cobalt complex remained in its initial stoichiometry when dissolved in acetonitrile, the successive reduction steps being therefore:

$$
\begin{aligned}
& \mathrm{Co}{ }^{\prime \prime} \mathrm{Br}_{2} \text { bpy }+\mathrm{e}^{-} \rightarrow \mathrm{Co} \text { 'Brbpy }+\mathrm{Br}^{-} \text {(wave } \mathrm{R}_{1} \text { ) } \\
& \text { Co'Brbpy }+\mathrm{e}^{-} \rightarrow \mathrm{Co}^{0} \text { bpy }+\mathrm{Br}^{-} \text {(wave } \mathrm{R}_{2} \text { ) }
\end{aligned}
$$

The stationary curves obtained by rotating disk voltammetry shifted toward more negative potentials when bromide concentration increased. A closer examination revealed that half-wave potentials were linear functions of the logarithm of bromide concentration and were shifted by about $60 \mathrm{mV}$ per decade of concentration for both waves. Such behavior was therefore consistent with the exchange of one bromide ion at each wave. The effect of free bromide ions on the stationary voltammograms of $\mathrm{CoBr}_{2}$ bpy recorded at a rotating disk electrode is presented in Figure 2. Importantly, the electrogenerated Co'Brbpy was found to be unstable on the timescale of a preparative electrolysis (few minutes). Under these conditions, it underwent disproportionation, which resulted 
in the observation of an overall 2 Faraday per mole reduction process.

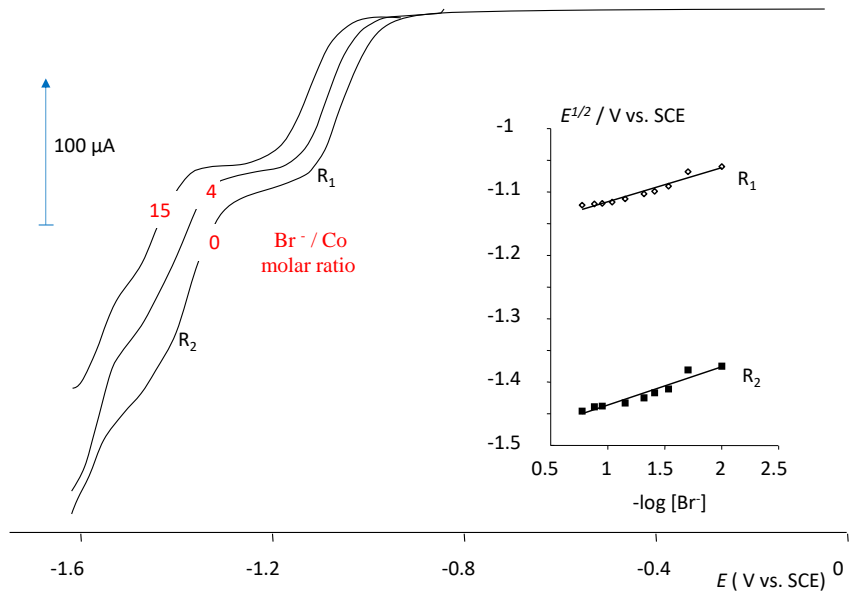

Figure 2. Effect of the free bromide concentration on stationary voltammgrams and on the corresponding half wave potential values for $\mathrm{CoBr}_{2}$ bpy 0.005 $\mathrm{mol} . \mathrm{dm}^{-3}$ in MeCN. Adapted from ${ }^{[11]}$

\subsubsection{Non-intuitive stabilization of cobalt(I) salts.}

In the following, we develop some examples of cobalt stabilizing effects that were assessed by cyclic voltammetry from unexpected partners (the electrode itself, a cyclodextrin architecture or zinc bromide salts) .

\section{a/ at a glassy carbon electrode}

The cobalt (I) species electrogenerated from $\mathrm{Co}^{\prime \prime}\left(\mathrm{BF}_{4}\right)_{2}$ precursor was found surprisingly stable several seconds at a glassy carbon working electrode when acetonitrile was used as solvent in agreement with a fully reversible wave (Fig.1, second cyclic voltammogram from the bottom). Unlike what was reported so far, the use of a co-solvent, a ligand, or additives were not required to stabilize the electrogenerated cobalt(I) species. Though the exact role played by the glassy carbon electrode has not been fully explained, this unprecedented stabilizing effect may be ascribed to the presence of carbonyl, hydroxy, or carboxylic groups at the electrode surface. Besides, the presence of halide ions such as bromide ions inhibited this stabilization effect. Moreover, such stabilization was not observed with other metals such as iron, nickel, copper, or zinc salts. Actually, the glassy carbon working electrode acts as a stabilizing surface with the advantage of being specific to cobalt cations. Another advantage lies in the fact that the electrochemical formation of $\mathrm{Co}^{0}$ species could be evidenced for the first time on the time-scale of slow cyclic voltammetry $(-1.16$ $\mathrm{V} / \mathrm{SCE}$ at $100 \mathrm{mV} / \mathrm{s})^{[13]}$ and in the absence of any added cosolvent or ligand.

$\mathrm{b} /$ in the presence of 6-Deoxy-6-N-(2-methyliminopyridine)beta-cyclodextrin as ligand

Alternatively, the electrogenerated cobalt $(I)$ species (obtained from the reduction of $\mathrm{CoX}_{2} ; \mathrm{X}=\mathrm{Br}$ or $\mathrm{BF}_{4}$ ) can be kinetically and thermodynamically stabilized by 6-Deoxy-6-N-(2methyliminopyridine)-beta-cyclodextrin (CD) as ligand (Figure 3).

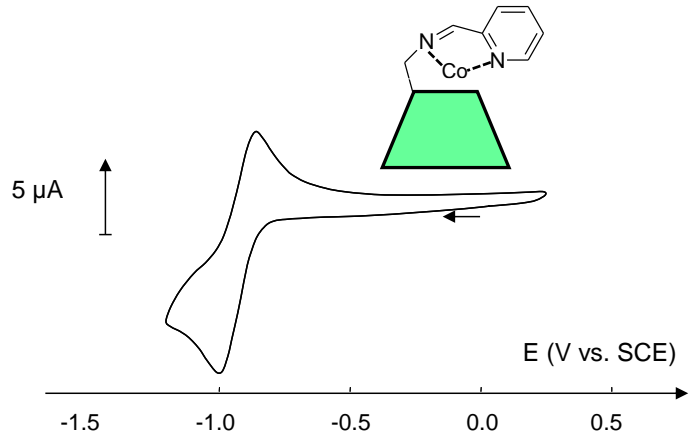

Figure 3. Cyclic voltammograms of $\mathrm{CoBr}_{2}(2 \mathrm{mM})$ in DMF at a glassy carbon electrode in the presence of 1 equiv. of 6-Deoxy-6-N-(2-methyliminopyridine)$\square$-cyclodextrin as ligand. Scan rate $100 \mathrm{mV} . \mathrm{s}^{-1}$. Adapted from ref [14]

The stability of the $\mathrm{Co}(\mathrm{I})$ complex obtained with this unconventional ligand could be compared to that obtained in the presence of excess bipyridine. However, the methyliminopyridine moiety which was grafted on the CD part can only be accounted as one pyridine ligand suggesting that the CD moiety participates to the overall coordination sphere for that cobalt complex. Indeed, it was shown that such stabilization only occurred when the iminopyridine and the CD moieties were covalently bound to each other. Though the presence of the iminopyridine ligand was required to afford this interesting behavior, the $C D$ moiety played a key role through weak interactions such as van der Waals forces, electronic effects, hydrophobic interactions, etc... ${ }^{[14]}$. Such cyclodextrin-based architectures are powerful tools in catalysis and sensor design ${ }^{[15]}$.

\section{$\mathrm{c} /$ in the presence of zinc bromide salts}

In DMF/pyridine $(9: 1, \mathrm{v} / \mathrm{v})^{[16]}$ or in $\mathrm{MeCN}^{[17]}$, it was demonstrated that the presence of zinc bromide also allowed stabilization of the electrogenerated $\mathrm{Co}^{\prime}$ species.

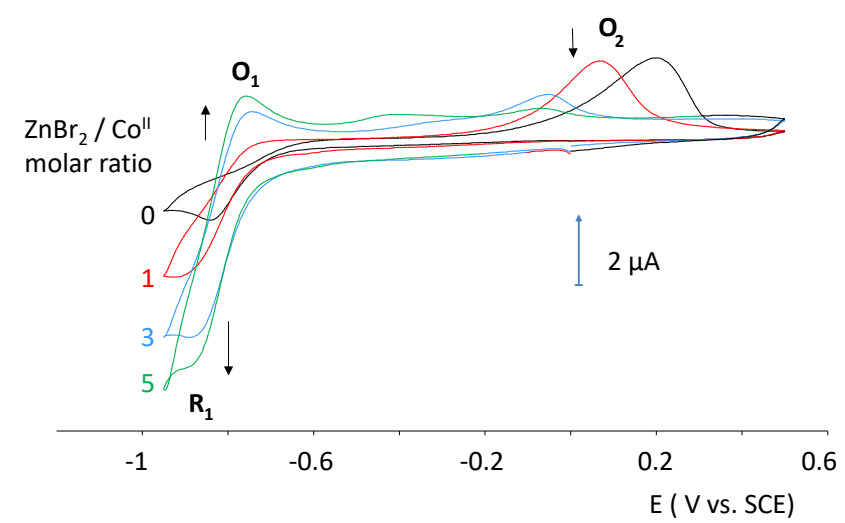

Figure 4. Effect of increasing amounts of $\mathrm{ZnBr}_{2}$ on the reversibility of the Co" reduction wave in $\mathrm{MeCN}$. $\left[\mathrm{CoBr}_{2}\right]=0.005 \mathrm{~mol} . \mathrm{dm}^{-3}$. Scan rate $0.2 \mathrm{~V}^{-\mathrm{s}^{-1}}$ 
Here again, this effect was explored by cyclic voltammetry, through the determination of the $\mathrm{Co}^{\prime}$ disproportionation rate constants as a function of $\mathrm{ZnBr}_{2}$ excess. As shown in Figure 4 for $\mathrm{MeCN}$, the stability of $\mathrm{Co}^{\prime}$ increased with the amount of zinc bromide in agreement with the appearance of $\mathrm{O}_{1}$ and the disappearance of $\mathrm{O}_{2}{ }^{[16]}$. Note that the increase in the reduction current of $R_{1}$ is linked to an increase in the concentration of the $\mathrm{Co}^{2+}$ species due to a reaction taking place between both $\mathrm{ZnBr}_{2}$ and $\mathrm{CoBr}_{2}$, and consisting of the transfer of bromide ions from cobalt(II) to zinc(II). More interestingly, $\mathrm{ZnBr}_{2}$ appeared to provide stronger stabilization of $\mathrm{Co}^{\prime}$ in acetonitrile than pyridine, exhibiting coupling reactions with a greater variety of electrophiles ${ }^{[18]}$. Interestingly, the cyclic voltammogram obtained by reduction of $\mathrm{Co}^{2+}$ in the presence of $\mathrm{Zn}^{2+}$, both electrochemically prepared, did not display any reversibility for $\mathrm{R}_{1}$ and no decrease in the oxidation current of $\mathrm{O}_{2}$ indicating that the presence of bromide ions was required to stabilize the $\mathrm{Co}^{+}$ species. Therefore, the stability of $\mathrm{Co}(\mathrm{I})$ in the presence of $\mathrm{ZnBr}_{2}$ may be explained by the possible formation of an intermediate bridged species of the type $\mathrm{Co}(\mathrm{I})-\mathrm{Br}-\mathrm{Zn}$. This also opened new perspectives to chemically prepare functionalized arylzinc compounds under mild conditions using simple cobalt catalyst and zinc dust ${ }^{[19]}$.

A synthetic overview of the stabilizing effects discussed in this paragraph is proposed in Figure 1.

\subsection{Exploring the reactivity of electrogenerated species.}

Carbon-carbon bond formation from substrates such as organic halides, olefins or carbonyls is a central issue in organometallic synthetic processes. The quest for milder reagents than e.g. magnesium or lithium to allow a good functional compatibility has motivated the screening of both the reducing properties and reactivity of notably palladium, nickel or cobalt catalysts. This paragraph deals with the electroanalytical characterization of the reactions (or reaction sequences) triggered by the electrochemical generation of such low valent metal species.

Metal Salen (Salen $=$ N,N'-bis(salicylidene)ethylenediamine) complexes are very interesting catalysts since they combine the reactivity of the metal and the structural versatility of the Salen ligand, easily amenable to a chiral moiety upon preparation from the parent chiral diamine $e^{[20]}$.

Nickel salen complexes have been thoroughly explored by D.G. Peters et al. for their capacity to promote the monoelectronic reduction of alkyl halides $\mathrm{RX}^{[21]}$. Indeed, the CVs display catalytic current increases for the $\mathrm{Ni}^{\prime \prime}$ reduction peak in the presence of excess $\mathrm{RX}$, strengthening the occurrence of an electron transfer as the initial step:

$\mathrm{Ni}^{\mathrm{il}}+\mathrm{e}-\rightarrow \mathrm{Ni}^{\mathrm{i}}$

$\mathrm{Ni}^{l}+\mathrm{RX} \rightarrow \mathrm{Ni}^{\prime \prime}+\mathrm{R}^{\bullet}+\mathrm{X}^{-}$

Another possible mechanism in keeping with this electrochemical behavior would involve the formation of $\mathrm{R}-\mathrm{Ni} \mathrm{N}^{\mathrm{III}}-\mathrm{X}$ intermediates, reducible at the same potential value than the original $\mathrm{Ni}^{\prime \prime}$ complex, thus displaying an ECE sequence. That possibility, originally suggested by $D$. Pletcher et $\mathrm{al}^{[22]}$, has not been confirmed (preparative electrolyses did not yield the expected EPR signal for the allkylnickel(III) complex ${ }^{[21]}$.

Cobalt-Salen catalyzed reductions of activated alkyl halides (haloacetates, iodoalkanes) have also been studied ${ }^{[5 a-c]}$ by these groups and the CVs essentially display the same electrochemical features as for $\mathrm{Ni}$-Salen, thus validating the overall mechanistic framework established with the latter.

The reactivity of $\mathrm{Cu}(\mathrm{I})^{[23]}$ (with tris(2-pyridylmethyl)amine (TPMA), tris[2-(dimethylamino)ethyl]-amine (Me6 $T R E N$ ) or N,N,N',N",N"pentamethyldiethylenetriamine (PMDETA) as ligand) and $\mathrm{Fe}(\mathrm{II})$ salen $^{[24]}$ complexes towards activated alkyl halides was also established from cyclic voltammetry, a major feature to assess the reversible activation/deactivation of radicals in classical (ATRP) or electrochemically-mediated (e-ATRP) atom transfer radical polymerization (ATRP), as illustrated in Scheme 2 . The reaction of the reduced metal complex on the activator is observed from the loss of reversibility at the backward scan (accounting for the consumption of $\mathrm{M}_{\mathrm{t}}^{\mathrm{n}}$ ), while the current increase of the reduction peak underlines the electron transfer from $M_{t}^{n}$ to $R-X$, thus regenerating $M_{t}{ }^{n+1}-X$.

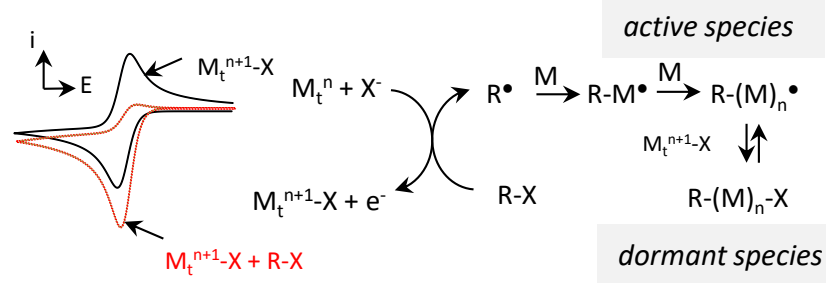

Scheme 2. Typical electrochemical behavior of $M_{t}{ }^{n} / R X$ couples used in ATRP and e-ATRP.

The activation of $\mathrm{C}\left(\mathrm{sp}^{2}\right)-\mathrm{X}$ bonds from Metal Salen complexes has been less effective, probably because the $\mathrm{C}\left(\mathrm{sp}^{2}\right)-\mathrm{X}$ bonds are stronger than their $\mathrm{C}\left(\mathrm{sp}^{3}\right)$ analogues (e.g. alkyl-Br bonds have dissociation energies of ca. $70 \mathrm{kcal} . \mathrm{mol}^{-1} \mathrm{vs} .84 \mathrm{kcal} . \mathrm{mol}^{-1}$ for aryl-Br bonds $\left.{ }^{[25]}\right)$. With this respect, relatively recent works have described the $\mathrm{Co}(\mathrm{I})$-Salen promoted reduction of hexachlorobenzene ${ }^{[26]}$ and bromo- or iodo-naphthalene ${ }^{[27]}$. In the latter work, the determination of the oxidative addition constants of $\mathrm{Co}(\mathrm{I})-$ Salen on iodo- and bromonaphthalene was achieved from the measurement (circles) and fitting (lines) of the reversibility of the $\mathrm{Co}(\mathrm{II}) / \mathrm{Co}(\mathrm{I})$ wave towards the concentration vs. time competitive parameter $[\mathrm{Ar}-\mathrm{X}] / \mathrm{v}$ (Figure 5). $[\mathrm{Ar}-\mathrm{X}] / \mathrm{v}$ is used as a kinetic parameter representing in a single variable the competitive effect of the time window explored (scan rate $v$ ) and concentration $([\mathrm{Ar}-\mathrm{X}])$ on the acceleration of the coupled chemical reaction responsible for the loss of reversibility. 


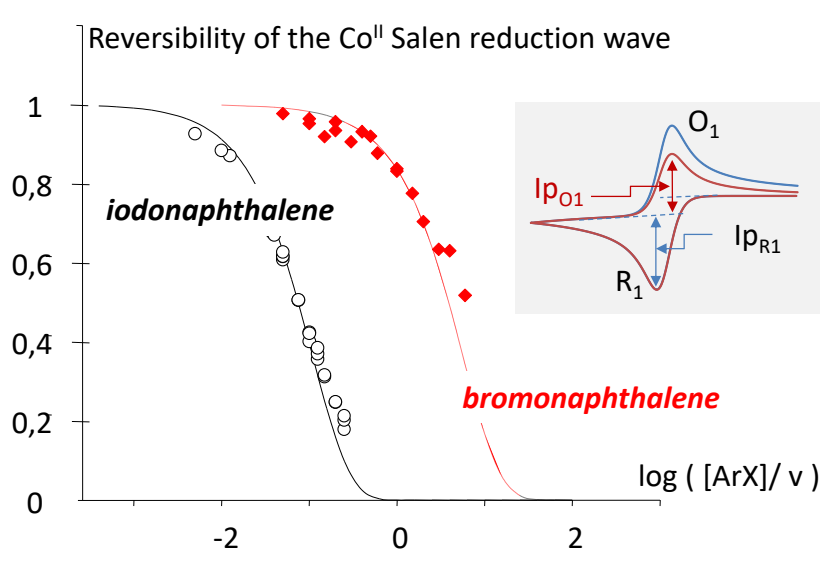

Figure 5. Plot and fit of the reversibility of the Co" salen reduction wave against $[\mathrm{Ar}-\mathrm{X}] / \mathrm{v}(\mathrm{v}=\mathrm{scan}$ rate), allowing the determination of the oxidative addition rate constants $\left(\mathrm{k}=18.8 \mathrm{M}^{-1} . \mathrm{s}^{-1}\right.$ for iodonaphthalene, $\mathrm{k}=0.35 \mathrm{M}^{-1} \mathrm{~s}^{-1}$ for bromonaphthalene). Adapted from Ref. [27]. Inset = schematic evolution of a reversible reduction wave for an EC mechanism, showing the measurement of the peak currents.

The reversibility was evaluated through the $I_{p}\left(O_{1}\right) / I_{p}\left(R_{1}\right)$ ratio at different scan rates and for various $[\mathrm{Ar}-\mathrm{X}] /[\mathrm{Co}$ "-salen] ratios. Calculated plots of $I_{p}\left(O_{1}\right) / I_{p}\left(R_{1}\right)$ against log $[A r-X] / v$ were obtained according to the following considerations:(i) the ratio $\left[\mathrm{Co}^{\prime} \text {-salen }\right]^{t} /[\mathrm{Col} \text {-salen }]^{0}$ is equal to $\mathrm{I}_{\mathrm{p}}\left(\mathrm{O}_{1}\right) / \mathrm{I}_{\mathrm{p}}\left(\mathrm{R}_{1}\right)$. (ii) $[\mathrm{Ar}-\mathrm{X}] /\left[\mathrm{Co}^{\prime}\right.$ salen] $>10$, which allows to consider a pseudo-first order reaction. (iii) $\mathrm{t}=$ reaction time is evaluated from the potential range $\Delta E$ scanned between $I_{p}\left(R_{1}\right)$ and $I_{p}\left(O_{1}\right)$ and the scan rate $v$. Then the pseudo-first order kinetic equation of the reaction between Co'-salen and $\mathrm{Ar}-\mathrm{X}$ can be written: [Co'-salen] $]^{\mathrm{t}} /\left[\mathrm{Co} \mathrm{C}^{\prime}-\right.$ salen $]^{0}=I_{p}\left(O_{1}\right) / I_{p}\left(R_{1}\right)=\exp \left(-k^{\prime} t\right)$ with $k^{\prime}=k[A r-X]$. Since $t=\Delta E / v$, the model used to fit the experimental points in Fig. 5 was obtained from the following equation: $I_{p}\left(O_{1}\right) / I_{p}\left(R_{1}\right)=\exp (-$ $\left.10^{\log (k \Delta E)+\log ([A r-X] V)}\right)$.

The effect of the coordination environment on the reactivity of electrogenerated $\mathrm{Ni}^{0}$ complexes has been described in several papers. Interestingly, the nature of the ligand was proven to affect the product distribution in the nickel-catalyzed electrochemical carboxylation of terminal alkynes ${ }^{[28]}$, suggesting that different intermediates are obtained from different Ni-ligand couples. This assumption was more quantitatively verified in the electrochemical coupling of vinylic halides, where the reversibility of the $\mathrm{Ni}^{\prime \prime} / \mathrm{Ni}^{0}$ was used in the $\mathrm{CVs}$ to calculate the rate constants and establish both their dependence on the nature of the halogen atom and also on the Ni-bipyridine stoichiometry $^{[29]}$ (Table 1).

Table 1. Oxidative addition rate constants of $\mathrm{Ni}^{0}$ on vinylic halides

\begin{tabular}{ccc}
\hline Ni Complex ${ }^{[a]}$ & $\begin{array}{c}\text { Rate constant } \mathrm{Ni}^{0}+ \\
\text { 2-bromo-2-butene } \\
\mathrm{M}^{-1} \cdot \mathrm{s}^{-1}\end{array}$ & $\begin{array}{c}\text { Rate constant } \mathrm{Ni}^{0}+ \\
\text { 2-chloro-2-butene } \\
\mathrm{M}^{-1} \cdot \mathrm{s}^{-1}\end{array}$ \\
\hline $\mathrm{NiBr}_{2}$ bpy & $>4000$ & $2500(\mathrm{Z}+\mathrm{E})$ \\
$\mathrm{Ni}\left(\mathrm{BF}_{4}\right)_{2}(\mathrm{bpy})_{3}$ & $885(\mathrm{Z}$ isomer $)$ & $785(\mathrm{Z}+\mathrm{E})$ \\
& $665(\mathrm{E}$ isomer $)$ & \\
& & \\
\hline
\end{tabular}

As recalled in Figure 1, cobalt complexes exhibit a very large variability in the stability of their low redox states, and this feature strongly affects their reactivity. Generally, the weaker the coordination of cobalt, the higher its capacity to break (or insert in) carbon-halogen bonds, namely $\mathrm{C}\left(\mathrm{sp}^{2}\right)-\mathrm{X}$ bonds. The $\mathrm{CoBr}_{2} \mathrm{bpy}$ complex was particularly interesting in this context, since oxidative addition on aromatic carbon-halogen bonds depended on the oxidation state of cobalt ${ }^{[11]}$. As shown in Figure 6 , the reaction of electrogenerated $\mathrm{Co}(\mathrm{I})$ on iodo-, bromo- and chlorobenzoates can be monitored by cyclic voltammetry.
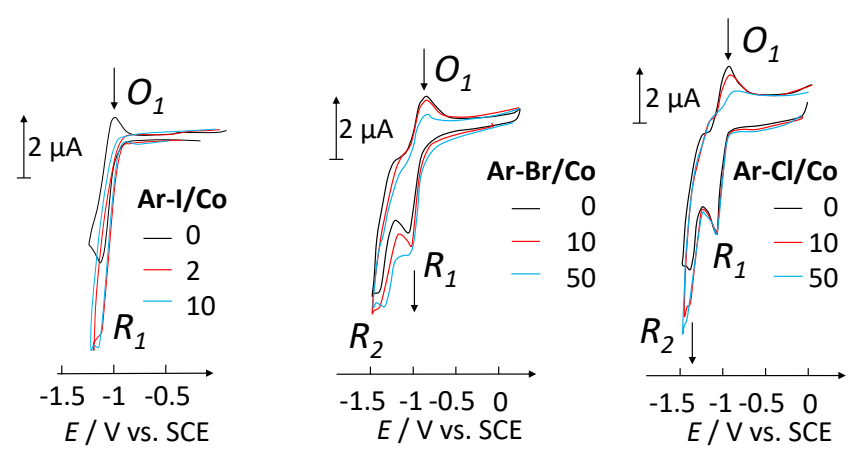

Figure 6. $\mathrm{CVs}$ of $\mathrm{CoBr}_{2}$ bpy $0.005 \mathrm{~mol} . \mathrm{dm}^{-3}$ in $\mathrm{DMF}$ in the presence of various molar excesses of respectively ethyl-4-iodobenzoate, ethyl-4-bromobenzoate and ethyl-4-chlorobenzoate (from left to right). Adapted from Ref. [11]

For the iodo and bromo derivatives, the $\mathrm{Co}(\mathrm{II}) / \mathrm{Co}(\mathrm{I})$ couple is the central electrochemical system involved through the evolution of waves $R_{1}$ and $O_{1}$ : upon addition of increasing amounts of aromatic halide, the current intensity decreased for $\mathrm{O}_{1}$ while that for $R_{1}$ displayed the opposite evolution, these two features being more pronounced for the iodo derivative; Ethyl-4-chlorobenzoate remained unreactive on electrogenerated $\mathrm{Co}(\mathrm{I}) \quad\left(\mathrm{R}_{1} / \mathrm{O}_{1}\right.$ unaffected) but an additional reduction wave appeared and increased at $R_{2}$, showing that electrogenerated $\mathrm{Co}(0)$ underwent oxidative addition on aromatic $\mathrm{C}\left(\mathrm{sp}^{2}\right)-\mathrm{Cl}$ bonds. For the iodoand bromo derivatives, this overall behavior was consistent with an oxidative addition preliminary step (decrease of $\mathrm{O}_{1}$ ) followed by the reduction of the intermediate $\mathrm{Ar}-\mathrm{Co}(\mathrm{III})-\mathrm{X}$ at the same potential $\left(R_{1}\right)$, resulting in an overall ECE system. A similar sequence was observed with the aromatic chloride, but this time centered on the $\mathrm{Co}(\mathrm{I}) / \mathrm{Co}(0)$ couple $\left(\mathrm{R}_{2}\right)$, featuring the corresponding $\mathrm{Ar}-\mathrm{Co}(\mathrm{II})-\mathrm{Cl}$ reduction wave at the same potential value $\left(R_{2}\right)$.

Palladium catalysis has been widely explored by A. Jutand et al. namely in the context of the reductive coupling of aromatic halides or triflates, or vinylic triflates with $\mathrm{CO}_{2}{ }^{[30]}$. The oxidative addition of these substrates on electrogenerated $\mathrm{Pd}^{0}\left(\mathrm{PPh}_{3}\right)_{2} \mathrm{Cl}$ was evidenced by the loss of reversibility of the $\mathrm{Pd}^{\prime \prime}\left(\mathrm{PPh}_{3}\right)_{2} \mathrm{Cl}_{2}$ reduction wave in cyclic voltammetry ${ }^{[31]}$. Since the review by $\mathrm{A}$. Jutand develops both mechanistic and electroanalytical aspects $^{[30]}$, we encourage the reader to look up this interesting and comprehensive overview of electrochemically explored palladium catalysis. 


\section{Electrochemical characterization of complex reaction sequences and late intermediates.}

In the previous paragraph, we have recalled how simple electrochemical approaches could provide crucial information on the stability and reactivity of electrogenerated species aimed at activating and catalysing electrosynthetic reductive processes. Electrochemical techniques may also allow a deeper mechanism characterization and help identify late reaction intermediates which result from the evolution of the electrogenerated species. Mechanistic frameworks have been established in molecular electrochemistry essentially by J.M. Savéant et al. to describe and model the influence of chemical reactions coupled to electron transfer steps ${ }^{[32]}$, namely those related to the above discussed distinction between ECE and disproportionation sequences $^{[33]}$. Nevertheless, in some cases the deciphering of complete mechanisms does not necessarily require expert knowledge in electrochemical concepts or techniques. Indeed, provided i) some intermediates display an electrochemical signature (i.e. can be electrochemically oxidized or reduced) and/or ii) complementary stepwise electrolyses can be performed, voltammetry may provide robust experimental evidences of the existence of even transient reaction intermediates, thus providing unassailable elements in the delineation of complex mechanisms. This is illustrated in the following examples selected from nickel and cobalt catalysis.

The activation and homocoupling of aromatic halides from nickel catalysts has been explored by $\mathrm{C}$. Amatore in a seminal paper ${ }^{[34]}$, and the mechanism proposed appeared to be a general reaction framework for the activation of $\mathrm{C}\left(\mathrm{sp}^{2}\right)$-halide substrates, like vinylic halides ${ }^{[29]}$ as illustrated in Figure 7. Actually, the sequence exhibits a series of electrochemical (steps (1), (3) and (6) in Figure 7) interwoven by chemical ((2), (4) and (5)) reactions. The stationary voltammograms accordingly displayed two reduction waves at $R_{1}$ (accounting for steps (1) and (6)) and $R_{2}$ (step (3)). The overall current intensity observed at wave $R_{2}$ increased with the $[\mathrm{R}-\mathrm{X}] /\left[\mathrm{Ni} \mathrm{H}^{\mathrm{I}}\right]$ ratio and finally reached a maximum value for higher [R-X] excesses; therefore, as long as the current at $R_{2}$ evolved with $R-X$ concentration, the catalytic process was kinetically controlled by either step (2) or step (4), i.e. the chemical reactions where $\mathrm{R}-\mathrm{X}$ is a substrate, considering that electron transfers (1), (3) or (6) were note rate-determining at such negative potential values. The maximum intensity and its stagnancy observed at higher $[\mathrm{R}-\mathrm{X}]$ excesses could be ascribed to a limitation by the only non-RX dependent chemical step, viz. the reductive elimination depicted as step (5).

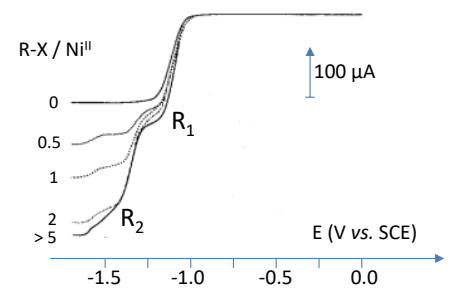

(1) $\mathrm{Ni}^{\prime \prime}+2 \mathrm{e}^{-} \rightarrow \mathrm{Ni}^{0}$

(2) $\mathrm{Ni}^{0}+\mathrm{R}-\mathrm{X} \rightarrow \mathrm{R}-\mathrm{Ni} \mathrm{Ni}^{-\mathrm{X}}$

(3) $\mathrm{R}^{-\mathrm{Ni}} \mathrm{Ni}^{-\mathrm{X}}+\mathrm{e}^{-} \rightarrow \mathrm{R}-\mathrm{Ni} \mathrm{i}^{+} \mathrm{X}$

(4) $\mathrm{R}-\mathrm{Nil}+\mathrm{R}-\mathrm{X} \rightarrow \mathrm{R}_{2}-\mathrm{Ni}{ }^{\prime \prime \prime}-\mathrm{X}$

(5) $\mathrm{R}_{2}-\mathrm{Ni}{ }^{\prime \prime \prime}-\mathrm{X} \rightarrow \mathrm{R}-\mathrm{R}+\mathrm{Ni}^{\mathrm{i}}-\mathrm{X}$

(6) $\mathrm{Ni}^{\prime}-\mathrm{X}+\mathrm{e}^{-} \rightarrow \mathrm{Ni}^{0}+\mathrm{X}$
Figure 7. Linear sweep voltammetry at a rotating disk electrode $(\omega=2000 \mathrm{rpm}$, scan rate $20 \mathrm{mV} \cdot \mathrm{s}^{-1}$ ) illustrating the successive rate determining steps in the nickel-catalyzed homocoupling of vinylic halides ${ }^{[29]}$

In these examples, the resolution of the kinetic equations provided the determination of the rate constants of steps (2), (4) and (5). However, a qualitative overview of the evolution of voltammograms with $\mathrm{R}-\mathrm{X}$ concentration was in itself a precious information of how catalysis proceeded in these cases.

The cobalt-catalyzed electroreductive coupling of aromatic halides with allylic acetates has been successfully achieved on various examples ${ }^{[35]}$. Since the electrogenerated cobalt $(I)$ was found reactive on both aromatic halides ${ }^{[6]}$ and allylic acetates ${ }^{[8]}$, the question arose of the actual nature of the mechanism, either consecutive (the oxidative addition would proceed on a preformed cobalt-allyl acetate complex) or competitive (the complexation of electrogenerated cobalt $(\mathrm{I})$ would compete with the oxidative addition). The oxidative addition apparent rate constants of a model aromatic halide on cobalt(I) were therefore calculated for two allyl acetate molar ratios ${ }^{[36]}$ (Table 2).

Table 2. Apparent oxidative addition rate constants of electrogenerated $\mathrm{Co}(\mathrm{I})$ on ethyl-4-bromobenzoate in the presence of different amounts of allyl acetate in MeCN/Pyridine (90/10, v/v).

Allyl acetate / Co initial molar ratio 10

Apparent rate constant ${ }^{[a]}$

$\mathrm{M}^{-1} \cdot \mathrm{s}^{-1}$

1260 220

[a] Determined from the reversibility of the Co(II) reduction wave in cyclic voltammetry

The allyl acetate concentration dependence of the apparent oxidative addition rate constant strengthened the occurrence of a competitive reaction between cobalt (I) and the aromatic halide or allyl acetate substrates (the concentration of the "reactive" Co(I) decreased upon complexation with the vinyl acetate, hence slowing down the oxidative addition on $\operatorname{ArX}$ ). In that context, the allylic acetate acted both as a stabilizing agent in a competitive manner towards oxidative addition and as a substrate on the arylcobalt(II) intermediate (Scheme 2).

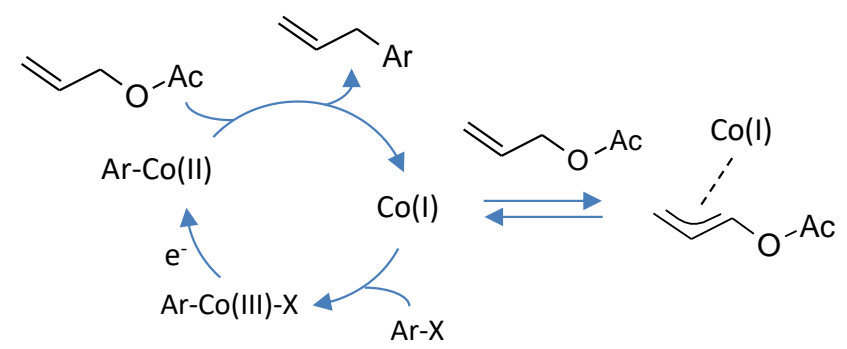

Scheme 2. Competitive reaction framework for the cobalt-catalyzed reductive coupling of aromatic halides and allylic acetates. 
This competitive situation was also encountered in the $\mathrm{CoBr}_{2}$ bpy catalyzed vinylation of aromatic halides ${ }^{[11]}$, where the vinyl acetate both stabilized the $\mathrm{Co}(\mathrm{I})$ complex and reacted on the arylcobalt(II) intermediate. These examples displaying competitive reactions illustrate the unique capacity of cyclic voltammetry in providing fast, quantitative and unambiguous information on the nature and kinetics of follow-up reactions, thus allowing to establish mechanisms from consolidated data.

\section{Concluding remarks}

In this review, we wished to highlight the benefits of using electroanalytical approaches to support electrosynthetic procedures in order to associate a stepwise identification of reactions to a preparative purpose. Indeed, electrode reactions, which generate species that may engage in several sequences either consecutively or competitively, can be characterized using routine techniques and apparatus to provide at least qualitative but robust information on the nature and fate of electrogenerated intermediates. The recent revival of organic electrosynthesis and the simultaneous development of accessible software establishing electronic structures and densities may appear as an alternative to electroanalytical approaches to propose plausible intermediates and reaction schemes. However, such computational methods cannot predict realistic mechanisms, unless reinforced by consolidated experimental approaches like those available from electroanalytical techniques

Keywords: Analytical electrochemistry • Cyclic voltammetry • Mechanism $•$ Reactivity $•$ Electrosynthesis

\section{References}

[1] (a) R. Francke, R. D. Little, Chem. Soc. rev. 2014, 43(8), 2492-2521; (b) S. Moehle, M. Zirbes, E. Rodrigo, T. Gieshoff, A. Wiebe, S. R. Waldvogel, Angew. Chem. Int. Ed. 2018, 57(21), 6018-6041; (c) K. D. Moeller, Chem. Rev. 2018, 118(9), 48174833.

[2] (a) E. J. Horn, B. R. Rosen, P. S. Baran, ACS Cent. Sci. 2016, 2(5), 302-308; (b) M. Yan, Y. Kawamata, P. S. Baran, Chem. Rev.2017, 117(21), 13230-13319.

[3] D. Pletcher, R. A. Green, R. C. D. Brown, Chem. Rev. 2018, 118(9), 4573-4591.

[4] M. Baizer, H. Lund, Organic electrochemistry: An introduction and a guide, $2^{\text {nd }}$ Ed., Marcel Dekker, New York, 1983.

[5] (a) K. S. Alleman, D. G. Peters, J. Electroanal. Chem. 1998, 451(1-2), 121-128; (b) K. S. Alleman, D. G. Peters, J. Electroanal. Chem. 1999, 460(1-2), 207-213; (c) L. J. Klein, K. S.
Alleman, D. G. Peters, J. A. Karty, J. P. Reilly, J. Electroanal. Chem. 2000, 481(1), 24-33; (d) B. H. R. Gerroll, S. P. Bird, E. T. Martin, M. S. Mubarak, D. G. Peters, ChemElectroChem 2018, 5(6), 902-910.

[6] O. Buriez, C. Cannes, J. Y. Nédélec, J. Périchon, J. Electroanal. Chem. 2000, 495(1), 57-61.

[7] O. Buriez, J. Y. Nédélec, J. Périchon, J. Electroanal. Chem. 2001, 506(2), 162-169.

[8] O. Buriez, E. Labbé, J. Périchon, J. Electroanal. Chem. 2003, 543(2), 143-151.

[9] C. Amatore, S. Gamez, A. Jutand, Chem. Eur. J. 2001 , $7(6), 1273-1280$.

[10] K. Kecili, O. Buriez, E. Labbé, J. Périchon, Electrochim. Acta 2005, 50(12), 2377-2384.

[11] L. Polleux, E. Labbé, O. Buriez, J. Périchon, Chem. Eur. J. 2005, 11(16), 4678-4686.

[12] C. Amatore, M. Azzabi, P. Calas, A. Jutand, C. Lefrou, Y. Rollin, J. Electroanal. Chem. 1990, 288, 45-63.

[13] O. Buriez, E. Labbé, J. Périchon, J. Electroanal. Chem. 2006, 593(1-2), 99-104.

[14] E. Deunf, O. Buriez, E. Labbé, J.-N. Verpeaux, C. Amatore, Electrochem. Comm. 2009, 11(1), 114-117.

[15] F. Hapiot, S. Tilloy, E. Monflier, Chem. Rev. 2006, 106(3), 767-781.

[16] S. Seka, O. Buriez, J. Périchon, Chem. Eur. J. 2003, 9(15), 3597-3603.

[17] S. Seka, O. Buriez, J. Y. Nédélec, J. Perichon, Chem. Eur. J. 2002, 8(11), 2534-2538.

[18] (a) G. Cahiez, A. Moyeux, Chem. Rev. 2010, 110(3), 14351462; (b) C. Gosmini, J. M. Begouin, A. Moncomble, Chem. Comm. 2008(28), 3221-3233.

[19] H. Fillon, C. Gosmini, J. Périchon, J. Am. Chem. Soc. 2003, 125(13), 3867-3870.

[20] (a) A. G. Doyle, E. N. Jacobsen, J. Am. Chem. Soc. 2005, 127(1), 62-63; (b) M. W. Fennie, E. F. DiMauro, E. M. O'Brien, V. Annamalai, M. C. Kozlowski, Tetrahedron 2005, 61(26), 62496265; (c) T. Kurahashi, Y. Kobayashi, S. Nagatomo, T. Tosha, T. Kitagawa, H. Fujii, Inorg.Chem. 2005, 44(22), 8156-8166.

[21] E. T. Martin, C. M. McGuire, D. G. Peters, Electrochem. Soc. Interface 2016, 25(2), 41-45.

[22] J. Y. Becker, J. B. Kerr, D. Pletcher, R. Rosas, J. Electroanal. Chem. 1981, 117(1), 87-99.

[23] A. J. D. Magenau, N. Bortolamei, E. Frick, S. Park, A. Gennaro, K. Matyjaszewski, Macromolecules 2013, 46(11), 4346-4353. 
[24] V. Bonometti, E. Labbé, O. Buriez, P. Mussini, C. Amatore, J. Electroanal. Chem. 2009, 633(1), 99-105.

[25] S. J. Blanksby, G. B. Ellison, Acc. Chem. Res. 2003, 36(4), 255-263.

[26] P. C. Gach, J. A. Karty, D. G. Peters, J. Electroanal. Chem. 2008, 612(1), 22-28.

[27] N. Faux, E. Labbé, O. Buriez, J. Y. Nédélec, J. Electroanal. Chem. 2007, 600(2), 359-363.

[28] E. Labbé, E. Dunach, J. Périchon, J. Organomet. Chem. 1988, 353(3), C51-C56.

[29] C. Cannes, E. Labbé, M. Durandetti, M. Devaud, J. Y. Nédélec, J. Electroanal. Chem. 1996, 412(1-2), 85-93.

[30] A. Jutand, Chem. Rev. 2008, 108(7), 2300-2347.

[31] (a) A. Jutand, S. Negri, Eur. J. Org. Chem. 1998(9), 18111821; (b) S. Torii, H. Tanaka, T. Hamatani, K. Morisaki, A. Jutand, F. Pfluger, J. F. Fauvarque, Chem. Lett. 1986(2), 169172.

[32] (a) J. M. Savéant, C. P. Andrieux, in Investigations of Rates and Mechanisms of Reactions, John Wiley \& Sons, New York, 1986; (b) J. M. Savéant, Elements of Molecular and Biomolecular Electrochemistry: An Electrochemical Approach to Electron Transfer Chemistry, John Wiley \& Sons, Inc., Hoboken, New Jersey, 2006.

[33] (a) J. Nadjo, J. M. Savéant, Electrochim. Acta 1971, 16(7), 887-\&; (b) J. M. Savéant, C. P. Andrieux, L. Nadjo, J. Electroanal. Chem. 1973, 41(1), 137-141; (c) C. Amatore, J. M. Savéant, J. Electroanal. Chem. 1977, 85(1), 27-46; (d) C. Amatore, J. M. Savéant, J. Electroanal. Chem. 1979, 102(1), 2140.

[34] C. Amatore, A. Jutand, L. Mottier, J. Electroanal. Chem. 1991, 306(1-2), 125-140.

[35] C. Cannes, E. Labbé, M. Durandetti, M. Devaud, J. Y. Nédélec, J. Electroanal. Chem. 1996, 412(1-2), 85-93.

[35] P. Gomes, C. Gosmini, J. Périchon, J. Org. Chem. 2003, 68(3), 1142-1145.

[36] P. Gomes, O. Buriez, E. Labbé, C. Gosmini, J. Périchon, J. Electroanal. Chem. 2004, 562(2), 255-260. 
Entry for the Table of Contents (Please choose one layout)

Layout 1:

MINIREVIEW

How simple
electroanalytical
approaches help identify
intermediates and
understand mechanisms in
electrosynthetic processes

How simple

electroanalytical

intermediates and

electrosynthetic processes

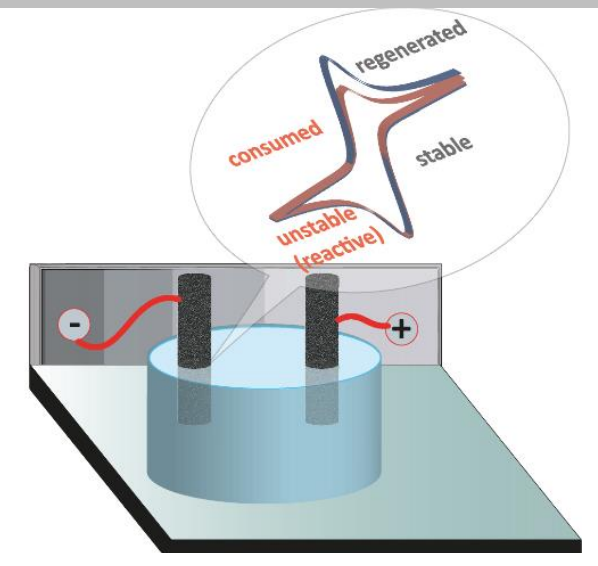

Eric Labbé* and Olivier

Buriez*

Page No. - Page No.

The fundamental input of analytical electrochemistry in the determination of intermediates and reaction mechanisms in electrosynthetic processes. 